OPEN ACCESS

Edited by:

Daniel Rittschof,

Duke University, United States

Reviewed by:

Holly Sweat,

Smithsonian Marine Station (SMS),

United States

Angelina G. Angelova,

American Society For Engineering

Education, United States

*Correspondence:

Jean-François Briand

briand@univ-tln.fr

${ }^{\dagger}$ Deceased

Specialty section: This article was submitted to

Marine Biology,

a section of the journa

Frontiers in Marine Science

Received: 23 July 2021 Accepted: 15 December 2021

Published: 03 February 2022

Citation:

Briand J-F, Pollet T, Misson B, Garnier C, Lejars M, Maintenay M,

Barry-Martinet $R$, Portas $A$, Ghiglione J-F and Bressy C (2022)

Surface Characteristics Together With

Environmental Conditions Shape Marine Biofilm Dynamics in Coastal

NW Mediterranean Locations.

Front. Mar. Sci. 8:746383.

doi: 10.3389/fmars.2021.746383

\section{Surface Characteristics Together With Environmental Conditions Shape Marine Biofilm Dynamics in Coastal NW Mediterranean Locations}

\author{
Jean-François Briand ${ }^{1 *}$, Thomas Pollet ${ }^{1,2}$, Benjamin Misson ${ }^{3}$, Cédric Garnier ${ }^{3 t}$, \\ Marlène Lejars' ${ }^{1}$, Marine Maintenay ${ }^{1}$, Raphaëlle Barry-Martinet ${ }^{1}$, Aurélie Portas ${ }^{1}$, \\ Jean-François Ghiglione ${ }^{4}$ and Christine Bressy ${ }^{1}$
}

'MAPIEM, EA 4323, Université de Toulon, La Garde, France, ${ }^{2}$ UMR ASTRE, Univ Montpellier, CIRAD, INRAE, Montpellier, France, ${ }^{3}$ Univ Toulon, Aix Marseille Univ., CNRS/INSU, IRD, MIO UM 110, Mediterranean Institute of Oceanography, La Garde, France, ${ }^{4}$ CNRS, Sorbonne Université, Laboratoire d'Océanographie Microbienne LOMIC, UMR 7621, Observatoire Océanologique de Banyuls, Banyuls-sur-Mer, France

Microbial colonization of artificial substrates in coastal areas, which concerns hull ships, sensors as well as plastic debris, is of huge significance to attain a rational environmental management. Some surface and environmental drivers of biofilm development have previously been described but their relative impact on the formation of biofilms remains unknown while crucial. Especially, there is no evidence of the relative importance of physical surface properties (wettability, roughness, smoothness) compared to seawater characteristics in driving biofilm abundance and diversity. In addition, few studies have considered the temporal evolution of this complex form of colonization, which often prevent to globally understand the process. Using experimental facilities in two Mediterrranean locations, a multidisciplinary approach including surface characterizations as well as seawaterquality analyses, flow cytometry and 165 rDNA metabarcoding, allowed for the identification of the main drivers of colonization for two antifouling (AF) coatings. One AF coating released copper (SPC1) while the other limit colonization thanks to physical properties, namely a low surface energy, roughness and smoothness (FRC1). Results were obtained over 75 days and compared to a control surface (PVC). Biofilm development was observed on all surfaces, with increasing density from AF coatings to PVC. Pionneer bacteria were dissimilar within all three surface types, however, communities observed on FRC1 converged toward PVC ones overtime, whereas SPC1 communities remained highly specific. A remarkably low and unique diversity was found on SPC1 during the experiment as Alteromonas accounted for more than $90 \%$ of the community colonizing this substrate until 12 days, and remained one of the co-dominant taxa of mature biofilms. Moreover, clear differences were found between geographical locations. Low nutrients and higher hydrodymanics in Banyuls bay resulted in less dense biofilms overall compared to Toulon, but also in a the slower dynamic of biofilm formation. This is illustrated by the 
persistence of pioneer Alteromonas but also Hyphomonadacae after 75 days on SPC1. We concluded that, even if local environmental conditions influenced the composition of biofilm communities, particular physical features may control the biofilm density but not the diversity, while copper releasing coating controlled both. In addition, it is evident from these results that sequential biofilm dynamics should carefully be considered as initial processes of formation differed from the long-term ones.

Keywords: biofilm, polymer surface, antifouling coatings, microbial ecotoxicology, molecular ecology

\section{INTRODUCTION}

Microbial colonization of immersed surfaces, i.e., biofilm growth, is a crucial process to control for the management of coastal areas. Antifouling (AF) coatings are designed to control the biofouling of ship hulls in order to limit the increase in hull roughness and vessel weight associated with hull colonization, which leads to an increase in fuel consumption and associated greenhouse gas emission, but also to reduce dry-docking and associated costs (Salta et al., 2013; de Carvalho, 2018). The colonization of surface by multicellular eukaryotes has been the focus of many studies but surfaces immersed in seawater always exhibited biofilms well before propagules reach them, due to high abundance of microorganisms compared to invertebrate larvae or algae spores. Then, interactions between biofilms and propagules influence macrofouling development (Hadfield, 2011; Salta et al., 2013; Lema et al., 2019), which strengthen the relevance to better decipher biofilm community drivers. Besides, biofilms are also involved in the transport of invasive species by ship hulls (Piola et al., 2009; Sardain et al., 2019), as well as in the degradation of polymers with the recent massive interest in marine plastic pollution (Jacquin et al., 2019; Oberbeckmann and Labrenz, 2020) or marine sensors maintenance (Delgado et al., 2021).

Some studies have reported a selective effect of substrate type on biofilm communities (Webster and Negri, 2006; Lee et al., 2008; Frere et al., 2018; Oberbeckmann et al., 2018; Ogonowski et al., 2018; Ding et al., 2019; Kesy et al., 2019; Muthukrishnan et al., 2019). Differences among conventional polymers are often limited, especially when immersion time exceeds weeks (Kirstein et al., 2018; Pinto et al., 2019). However, physico-chemical substrate characteristics are scarcely measured in field studies and, consequently, conclusions on their role in shaping biofilm community composition remained putative as they are only based on laboratory studies using bacterial strains (Genzer and Efimenko, 2006). Studies on biofilm communities colonizing AF coatings have essentially targeted biocidal paints (Self Polishing Coatings or SPC), generally showing specific effects after endpoint studies with different immersion time, from weeks (Briand et al., 2012; Camps et al., 2014; Sathe et al., 2016; Yang et al., 2016a,b; Briand et al., 2017; Sathe et al., 2017; Dobretsov et al., 2018) to months (Muthukrishnan et al., 2014; von Ammon et al., 2018; Catão et al., 2019). Fouling Release Coatings (FRC) are AF coatings with specific physical surface properties such as a low roughness and elastic modulus. They were developed to decrease the impact on marine ecosystems associated to the release of biocides by conventional AF coatings (Lejars et al., 2012). FRC remained poorly studied in terms of colonizing community, even if they are known to limit their colonization to microorganisms. Their study represents a great opportunity to specifically decipher the relative physical and chemical (biocide) effects that surface characteristics have on biofilm communities.

Highly abundant and diversified communities have been described on artificial surfaces, exhibiting dissimilar profiles depending on immersion locations (Briand et al., 2012; Oberbeckmann et al., 2016; Curren and Leong, 2018; Lema et al., 2019; Muthukrishnan et al., 2019; Zhang et al., 2019). However, (i) only a few studies included several locations with relevant measures of seawater parameters; (ii) early stages of bacterial colonization were mostly sampled; (iii) the relative influence of the substrate properties, never measured, and (iv) the environmental conditions remained often difficult to interpret as immersion time and location differed from one study to another.

In this study, we intend to decipher the relative contribution of substrates and environmental parameters in prokaryotic biofilm community dynamics. Polyvinyl chloride (PVC) was chosen as a reference, and immersed together with a FRC and a SPC at two North-western French Mediterranean sites (Toulon and Banyuls bays). FRCs are surfaces with a low surface energy, roughness and elastic modulus which limit the adhesion of organisms and enhance the fouling release properties. FRC1 is an ambiguous smooth surface composed of a polydimethylsiloxane (PDMS)-based elastomer and an amphiphilic additive, which is able to diffuse at the surface to provide both hydrophilic and hydrophobic properties (Duong et al., 2015) and disturbs the settlement of marine organisms. SPC1 contains biocides, mainly copper derivatives (dicopper oxide, copper pyrithione and zinc oxide), which are released into the seawater at a constant rate (Marceaux et al., 2018). Immersion during 75 days was monitored by eight sampling times at Toulon while only toward the end of the experimental Banyuls. Wettability and surface roughness of the substrates, as well as seawater parameters including trace metal elements, were measured. Biofilm dynamics was studied both in terms of abundance (Flow cytometry) and diversity (16S rDNA metabarcoding).

\section{MATERIALS AND METHODS}

\section{Experimental Design, Immersion Sites, and Environmental Variables}

Forty two panels $(5 \times 5 \mathrm{~cm})$ for each of the sandblasted PVC, the commercial biocidal coating called SPC1 and the commercial 
fouling release coating called FRC1 were immersed for 1-75 days in a semi-enclosed basin in the military harbor in the Bay of Toulon $\left(43^{\circ} 06^{\prime} 25^{\prime \prime} \mathrm{N}\right.$; $\left.5^{\circ} 55^{\prime} 41^{\prime \prime} \mathrm{E}\right)$ (18th June-1st September 2015). A static permanent raft enabled the immersion of panels at 1-m depth and seven sampling times were chosen: $1,4,8,12,20$, 28 , and 75 days. The immersion of 6 panels of the three substrates was also carried out within the bay of Banyuls-sur-Mer with only one sampling time after 75 days. A metallic frame was hung under the Oceanographic buoy SOLA, allowing the immersion of panels at $2 \mathrm{~m}$ ' depth. This site is located $1 \mathrm{~km}$ off the coast with a depth of $27 \mathrm{~m}\left(47^{\circ} 27^{\prime} 13^{\prime \prime} \mathrm{N} ; 03^{\circ} 32^{\prime} 360^{\prime \prime} \mathrm{E}\right)$. Due to the very low turbidity of the sites allowing similar light availability, and the lack of water column stratification, immersion at 1 or $2 \mathrm{~m}$ ' depth should be considered as similar. In addition, at each site, all the coupons were directed in the same way without any possible rotation. FRCs are surfaces with a low surface energy, roughness and elastic modulus which limit the adhesion of organisms and enhance the fouling release properties. FRC1 is an ambiguous smooth surface composed of a polydimethylsiloxane (PDMS)-based elastomer and an amphiphilic additive, which is able to diffuse at the surface to provide both hydrophilic and hydrophobic properties (Duong et al., 2015) and disturbs the settlement of marine organisms. SPC1 contains biocides, mainly copper derivatives (dicopper oxide, copper pyrithione and zinc oxide), which are released into the seawater at a constant rate (Marceaux et al., 2018). For all the substrates and conditions, half of the panels were dedicated to flow cytometry analyses and the other to metabarcoding analyses, all in triplicates.

For each sampling time point at Toulon, water temperature, $\mathrm{pH}$ and salinity were measured using a Hydrolab ${ }^{\circledR}$ DS5X probe (Hatch Hydromet, United States). Dissolved organic carbon (DOC) and total nitrogen (TN) were analyzed on a TOC-VCSH analyzer (Shimadzu) (Oursel et al., 2013). Nutrients $\left(\mathrm{NO}_{3}{ }^{-}\right.$, $\left.\mathrm{PO}_{4}{ }^{3-}, \mathrm{Si}(\mathrm{OH})_{4}\right)$ were analyzed using standard colorimetric methods for seawater (Coclet et al., 2018). Data from the same environmental variables were obtained at Banyuls-sur Mer from the SOMLIT website. ${ }^{1}$

Finally, trace metal $(\mathrm{Cd}, \mathrm{Cu}, \mathrm{Pb}, \mathrm{Zn})$ concentrations were determined at the two sampling sites by voltammetry on fully automated Metrohm/Ecochemie system (Cindric et al., 2015).

\section{Initial Substrates Characterization}

Wettability was evaluated by measuring static water contact angles $\theta$ stat, using a DIGIDROP contact angle meter from GBX Scientific Ltd. (United Kingdom) equipped with a syringe and a flat-tipped needle. The substrates were previously cleaned with deionized water and dried under ambient conditions for $48 \mathrm{~h}$ before measurements. The reported $\theta$ stat values were an average of five individual measurements, made on $1 \mu \mathrm{L}$-droplets of deionized water, deposited on different regions of the same substrate. Dynamic contact angle measurements experiments were also carried out by the advancing-receding drop method. A $1 \mu \mathrm{L}$-droplet is first deposited at the surface, keeping the needle inside the droplet. Then, the liquid is slowly dispensed until a final drop volume of $5-10 \mu \mathrm{L}$, followed by a withdrawal at a

${ }^{1}$ https://www.somlit.fr/ rate of $0.75 \mu$ L.s-1. For each coating, the reported advancing $(\theta \mathrm{a})$ and receding $(\theta \mathrm{r})$ water contact angles were the average values obtained from 1 cycle of advancing-receding of 5 deionized water drops. The hysteresis $\mathrm{H}(\mathrm{H}=\theta \mathrm{a}-\theta \mathrm{r})$ was also calculated.

Surface roughness profiles were measured by a contact type stylus surface profiler Formtalysurf 50 from Taylor Hobson Ltd. (United Kingdom) using a $2 \mu \mathrm{m}$-radius tip and a $0.1 \mu \mathrm{m}$-radius diamond tip with a minimum applicable $1 \mathrm{mN}$-stylus load. The stylus moved across $15 \mathrm{~mm}$-length of the substrate at a constant velocity of $0.50 \mathrm{~mm} . \mathrm{s}-1$ to obtain surface height variations. The arithmetic mean deviation values of roughness $(\mathrm{Ra})$ and waviness (Wa) were assessed from the average of three measurements. A microroughness filter $\lambda s$ is currently used to eliminate from the primary profile, the roughness which is not specific to the sample, but which is generated by the external environment, in particular by the background noise of the device. In other words, this filter makes it possible to compare the results provided by measuring devices of different manufacturers. A $\lambda$ s value of $0.0025 \mathrm{~mm}$ was taken for all samples. $\lambda c$ is an essential parameter since it allows to discriminate the roughness from the waviness of the primary profile. The choice of the cut-off theoretically depends on the nature of the profile (periodic or aperiodic) and its structure. In the ISO 4288-1996 standard, there are tables that allow you to know what value to give to the cut-off depending on the type of profile. Once the analysis is finished, the choice of the cut-off is checked again by comparing the Ra values obtained. In our case, the selected cut-off was $\lambda c=0.8 \mathrm{~mm}$ because the Ra values of coatings were comprised between 0.1 and $2 \mu \mathrm{m}$.

\section{Heterotrophic Prokaryotes Abundance}

For each sampling points, three panels were used to estimate abundances of heterotrophic prokaryotes by flow cytometry (Camps et al., 2014; Briand et al., 2017; Pollet et al., 2018; Catão et al., 2019). Panels were totally scraped using sterile scalpels and the collected biofilms were fixed with $4 \mathrm{ml}$ of a $2 \%$ formaldehydesolution prepared in sterile artificial seawater (ASW). Samples were quickly frozen in liquid nitrogen and maintained at $-80^{\circ} \mathrm{C}$ until analysis. Prior to the analysis, an experimental procedure was applied to release and separate the microbial cells from the EPS matrix, including sodium pyrophosphate and Tween ${ }^{\circledR} 80$ addition and centrifugation step (Camps et al., 2014). Results were then gated by cell size using fluorescent beads and only cells under $2 \mu \mathrm{m}$ were considered. Abundances of hetrotrophic prokaryotes were estimated using a $\mathrm{BD}$ Accuri $^{\mathrm{TM}}$ C6 flow cytometer (BD Biosciences) using Sybr green. Data were acquired using BD Accuri CFlow Plus software and abundances were expressed as number of cells per $\mathrm{cm}^{-2}$. Data on PVC were published alone before (Pollet et al., 2018).

\section{DNA Extraction, Amplification, and Sequencing}

For each sampling points, three panels were used for DNA extraction. Panels were totally scraped and biofilms were immediately dropped into liquid nitrogen and maintained at $80^{\circ} \mathrm{C}$. DNA was extracted using PowerBiofilm DNA isolation Kits (Qiagen) following the supplier's instructions. 
The V4 region of the bacterial and archaeal $16 \mathrm{~S}$ rRNA genes was targeted. The $16 \mathrm{~S}$ forward primer $515 \mathrm{Y}$ (GTGYCAGCMGCCGCGGTAA) and the 16S reverse primer 926R (CCGYCAATTYMTTTRAGTTT) (Parada et al., 2016) were chosen due to the high coverage of the prokaryotic diversity, including Archaea (Pollet et al., 2018). The PCR reaction (50 $\mu \mathrm{L}$ ) contained $10 \mu \mathrm{L}$ of $5 \times$ HotStar HiFidelity PCR buffer, $1 \mu \mathrm{M}$ of each primer, $2.5 \mathrm{U}$ of HotStar High Fidelity DNA polymerase and approximately $2 \mathrm{ng}$ of DNA. The following thermal cycling scheme was used: initial denaturation at $95^{\circ} \mathrm{C}$ for $5 \mathrm{~min}, 25$ cycles of denaturation at $95^{\circ} \mathrm{C}$ for $45 \mathrm{~s}$, annealing at $50^{\circ} \mathrm{C}$ for $1 \mathrm{~min}$, followed by extension at $72^{\circ} \mathrm{C}$ for $1 \mathrm{~min}$. The final extension was carried out at $72^{\circ} \mathrm{C}$ for $10 \mathrm{~min}$. Negative controls were performed by using the reaction mixture without template. Following the PCR step including controls, amplicons were cleaned and concentrated using 1X magnetic Agencourt AMPure XP beads (Beckman Coulter, Brea, CA). Concentrated DNA was quantified by PicoGreen fluorescence assay (Quant-iT ${ }^{\mathrm{TM}}$ PicoGreen $^{\circledR}$ dsDNA Assay Kit, Thermo Fischer Scientific) and pooled at equimolar concentrations. The equimolar mix was sequenced by GENOSCREEN (Lille, France) using Miseq Illumina $2 \times 250$ bp chemistry.

\section{Sequencing Data Processing}

Sequence processing and quality control were used using DADA2 software on R (Callahan et al., 2016). DADA2 was performed on primer-free reads to eliminate poor quality reads. After dereplication and learn error rates determination using default settings to remove sequences containing potential errors, chimeras were also removed. Paired end reads were merged to construct amplicon sequence variants (ASVs) for prokaryotic communities. ASVs were taxonomically assigned using SILVA 16S rDNA gene reference database (release 138). Chloroplast, mitochondrial, unclassified and singletons sequences were excluded from final dataset. Data on PVC were published alone before but using MOTHUR (Pollet et al., 2018).

\section{Statistical Analyses}

The ASV table from DADA2 was converted to biom format and imported in phyloseq (v.1.36.0) in $\mathrm{R}$ for data visualization and statistical analysis. Samples were rarefied with relative normalization method and ASV read counts were aggregated on the genus level. Using the rarefied dataset, alpha and beta diversity analyses were conducted with Vegan package (v.2.5-7). We examined the diversity models by exploring three different metrics which are the chao1, Shannon and Pielou indices. Differences in the ASV diversity, as well as prokaryotic densities determined by flow cytometry, were analyzed using one-way ANOVA followed by Tukey Honest Significant Difference (HSD) test $(p<0.05)$. Bray Curtis dissimilarity matrices were computed and used to generate non-multidimensional scaling (NMDS) to visualize the distribution of samples. Permutational analysis of variance (PERMANOVA) tests were carried out following Site, Material and Time as factors. Regression of supplementary environmental variables to ordination axes in unconstrained ordination (NMDS) was calculated with the envfit function (Vegan). Biomarkers, corresponding to differentially abundant taxa between coatings and sites, were identified with linear discriminant analysis (LDA) with effect size (LEfSe) (Segata et al., 2011) in the Galaxy environment (GENOTOUL Platform). LDA > 3.5 was applied for selection.

Network co-occurrence analysis was performed with CONET plugin (Faust and Raes, 2016) within Cytoscape version 3.8.2 (Shannon et al., 2003). Significant correlations between ASVs (positive and negative) were obtained by a combination of Spearman and Pearson correlations and Bray-Curtis or KullbackLeibler dissimilarities, selecting the 200 top and bottom edges in the automatic threshold. CoNet was used for rows shuffling and detection of only correlations with $p$-value $<0.05$ after Bonferroni test correction and bootstrap filtering of unstable edges (Brown method for $p$-value merge).

\section{RESULTS}

\section{Seawater Parameters in the Two Mediterranean Areas}

Temperature, salinity, $\mathrm{pH}, \mathrm{DOC}$ and $\mathrm{TN}$ were similar at the two sites showing typical North-Western Mediterranean values (Supplementary Table 1). Conversely, both nutrients and dissolved metals exhibited higher concentrations at Toulon. While nitrates and phosphates were near the detection limits $(0.01 \mu \mathrm{M})$ at Banyuls, they reached values as high as 1.98 and $0.14 \mu \mathrm{M}$ at Toulon, respectively. The enrichment factor in Toulon with reference to Banyuls was higher for metals, reaching 10-20 for $\mathrm{Cd}, \mathrm{Pb}$ and $\mathrm{Cu}$ and as high as 30-60 for $\mathrm{Zn}$.

\section{Initial Surfaces Roughness and Wettability}

PVC and SPC1 were rougher (highest Ra values) than the FRC1 (Supplementary Table 2). In addition, the waviness (Wa) showed that the rough PVC surface had more peaks (lower Wa) than the SPC1 surface and the FRC1. FRC1 presented a hydrophobic surface $\left(\theta\right.$ stat and $\left.\theta \mathrm{a}>100^{\circ}\right)$, and a high hysteresis $(\mathrm{H})$ indicated an heterogeneous surface. Due to the presence of amphiphilic additives, the FRC1 surface is expected to have a chemical surface reorganization upon contact with water, with different degrees of hydrophilicity depending on the amount of hydrophobic and hydrophilic phases (Duong et al., 2015). Despite its inert surface, the PVC presented similar behavior than FRC1 with high hydrophobicity and hysteresis. This behavior could be explained by its higher roughness which limits the spreading of the water drop and retains water in asperities during its removal. SPC1 exhibited a hydrophilic surface with a lower hysteresis.

Contact angle measurements could not be carried out after the colonization occurred.

\section{Density Dynamics of Biofilm Hetrotrophic Prokaryotic Communities for 75 Days}

Densities as high as $3.5 \times 10^{4}$ cells $/ \mathrm{cm}^{2}$ could be observed after a day for both the reference PVC surface and FRC1 whereas SPC1 value remained significantly lower $\left(6.7 \times 10^{3}\right.$ cells $/ \mathrm{cm}^{2}$, 

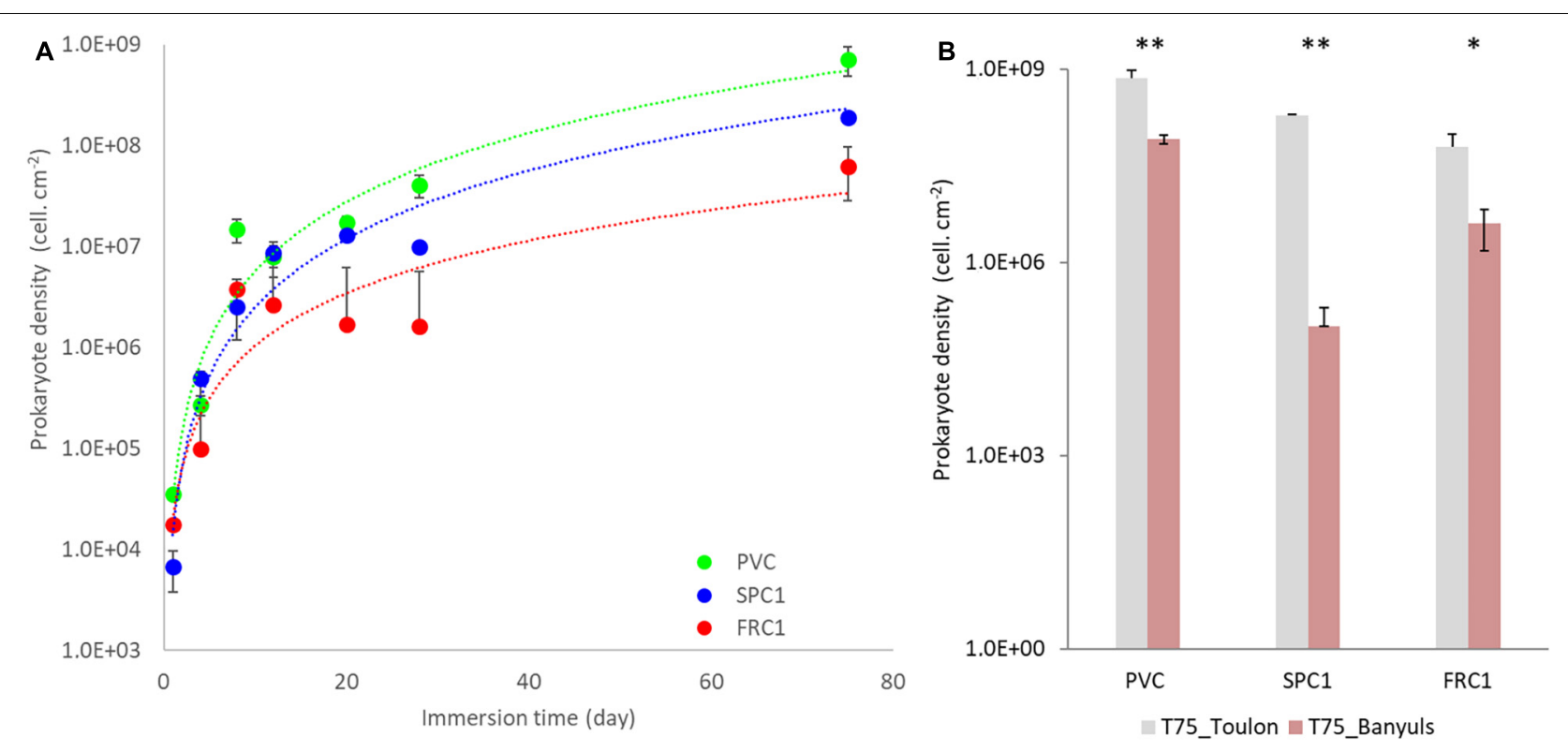

FIGURE 1 | Prokaryotic density colonizing PVC as well as two AF coatings (SPC1 and FRC1) from 1 to 75 days at Toulon bay (A) and after 75 days only at Banyuls bay (B) using Flow cytometry analyses. Statistical differences between sites were shown as follows: ** $(p<0.01),{ }^{*}(p<0.05)$.

$p<0.05$ ) at Toulon (Figure $\mathbf{1}$ and Supplementary Figure $\mathbf{1}$ ). The progressive increase of densities for all the surfaces led to significantly lower values for FRC1 $\left(6.3 \times 10^{7}\right.$ cells $\left./ \mathrm{cm}^{2}\right)$ and SPC1 $\left(1.9 \times 10^{8}\right.$ cells $\left./ \mathrm{cm}^{2}\right)$ compared to PVC $\left(7.2 \times 10^{8}\right.$ cells $\left./ \mathrm{cm}^{2}\right)$ after 75 days $(p<0.05)$. At Banyuls, FRC1 showed higher densities compared to SPC1, both of them significantly lower than PVC at T75 too $(p<0.05)$. Whatever the substrate, densities at Banyuls were overall lower than their counterparts at Toulon $(p<0.05)$.

\section{$\alpha$-Diversity for 75 Days at Toulon and Banyuls}

Numerous AF coatings samples exhibited low biomass, leading to amplification issues (SPC1 and FRC1 at T1, one PVC replicate at both T1 and T75 at Toulon, one FRC1 replicate at Banyuls) The Illumina Miseq run produced 829,149 paired-end reads. 2324 ASVs could be generated after clustering. Archaea were excluded $(<0.5 \%)$.

Both richness (Chaol) and diversity indices (Shannon and Pielou) showed the same temporal and surface relative trends at Toulon, with less significant differences for richness (Figure 2, ANOVA and Post hoc Tukey test, Supplementary Table 3). Alpha-diversity for the reference surface (PVC) rapidly increased and remained high and constant. Exhibiting very low values at T4 and T8 for SPC1, all the SPC1 and FRC1 indices showed a significant increase $(p<0.0001)$ with a lag of several days depending on the indices for the latter. Only after 75 days of immersion, induce showed no significant difference at both sites.

\section{Dynamics of the $\beta$-Diversity for 75 Days at Toulon}

Dissimilar temporal dynamics from T1 to T75 could be observed (Figure 3). Although communities on FRC1 and PVC tended to converge with time, SPC1 remained specific until T75, showing more similarity with early PVC ones.

At $\mathrm{T} 1$, the co-dominance of three genera was reported on PVC: Oleibacter sp., a potential hydrocarbonoclaste taxa among the Saccharospirillaceae (Gammaproteobacteria), Alteromonas spp. (Alteromonadaceae, Gammaproteobacteria) and Tenacibaculum spp. (Flavobacteriaceae, Bacteroidia) (37, 18 , and $7 \%$ of the sequences, respectively) (Figure 4). Other Flavobacteriaceae represented also a significant part of the early community on PVC, with Polaribacter and Dokdonia or Rhodobacteraceae including Tateyamaria. Then Oleibacter and Alteromonas decreased rapidly with the late emergence of Candidatus Endoecteinascidia (Piscirickettsiaceae). The increase of Alphaproteobacteria was noticed in parallel, mainly Rhodobacteraceae (18\%, especially unclassified, Ruegeria or Tatayemaria) and Cyanobacteria (17\%, mainly Xenococcus and an unknown Phormidesmiaceae) together with the keeping of Flavobacteriaceae (13\%, mainly Tenacibaculum, unclassified and Gilvibacter).

SPC1 exhibited a remarkable profile with Alteromonas (Gammaproteobacteria) accounting for more than $80 \%$ of the sequences until T8 (Figure 4). Among them, A. genovensis, A. gracilis, A. macleodii, A. mediterranea and unidentified species could be noticed. A. gracilis represented around $30 \%$ of Alteromonas reads at T4 and A. genovensis represented around $10 \%$ of Alteromonas reads at $\mathrm{T} 4$ and $\mathrm{T} 8$, before Alteromonas spp. was only detected (Supplementary Figure 2). Aestuariibacter, (Alteromonadaceae) and Marinobacter (Marinobacteraceae) remained between 4 and $23 \%$ of the reads all along the sampling time (highest $\%$ were reached at T12). A third Gammaproteobacteria, displayed similar percents. Together, the three Gammaproteobacteria represented $70 \%$ of the reads until 

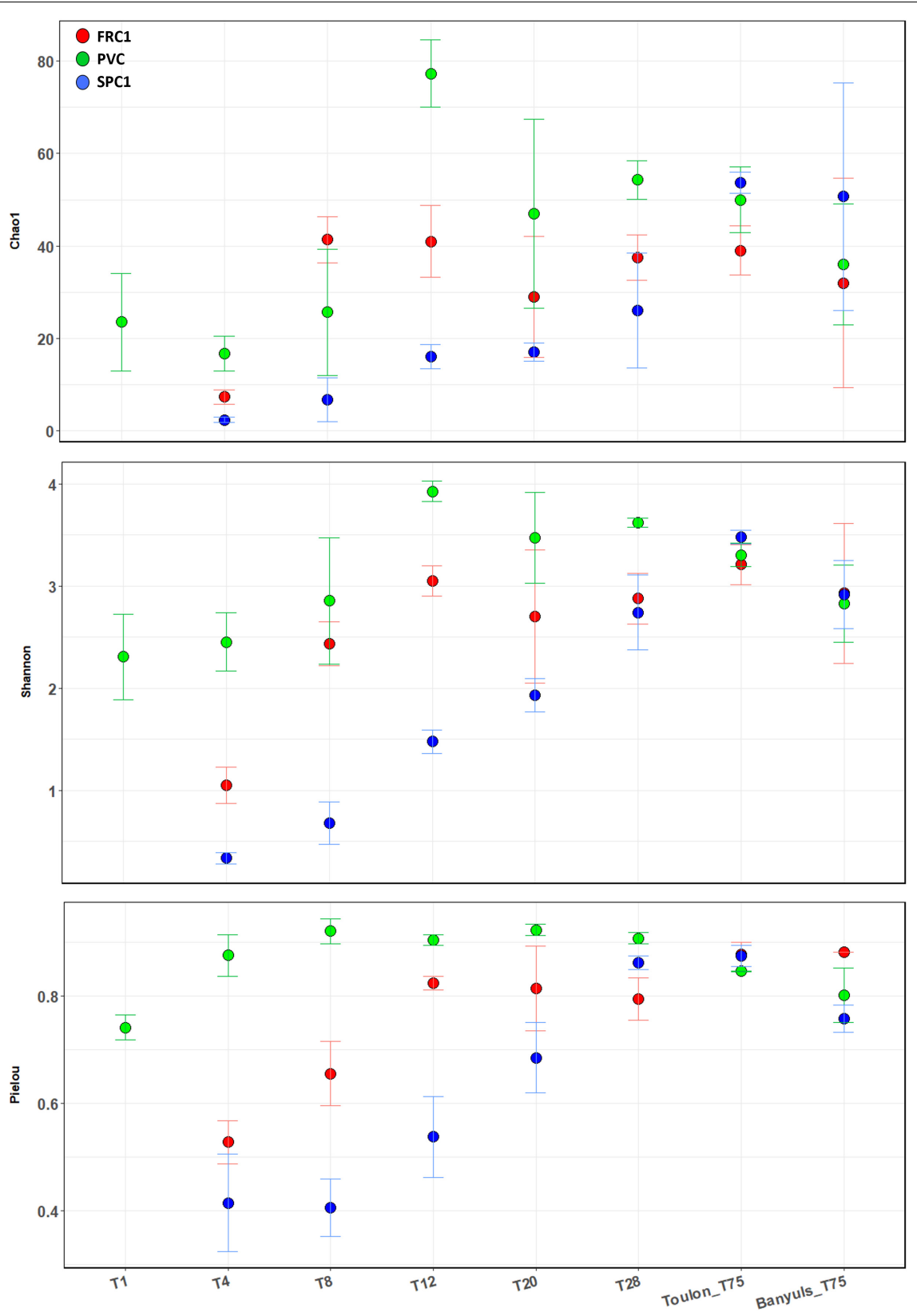

FIGURE 2 | Alpha-diversity indexes (Chao1, Shannon, and Pielou) corresponding to the prokaryotic communities on the different substrates (PVC and two AF coatings, SPC1 and FRC1), time and site (T1-T75 at Toulon bay and T75 only at Banyuls bay). Error bars stand for standard deviations. ANOVA and post hoc Tuckey tests were shown in Supplementary Table 3.

T20. The progressive diversification of the community observed from T20 lead to the dominance of the Flavobacteriaceae, reaching $23-32 \%$ of the reads at T75 (mainly Aurantivirga, but also Aureisphaera and Croceitalea). Together with Alteromonas (7\%) and Aestuaribacter (7\%), Erythrobacter (Sphingomonadaceae), SM1A02 (Phycisphaeraceae), Rhodobacteraceae, especially unclassified and Loktanella, were the most represented taxa.

Communities on FRC1 were dominated by Alteromonas ASVs as for SPC1 (73-26\%) and also Oleibacter as for PVC (17-2\%) until T8 (Figure 4). 15\% of Alteromonas reads were identified as A. gracilis at T4 before Alteromonas spp. was only detected (Supplementary Figure 2). Similarly to SPC1, Aestuariibacter completed the early community (6-26\%). Communities on FRC1 underwent a quicker and higher diversification compared to SPC1, and Alteromonas became nearly undetectable at T75. In addition, Methyloligellaceae (Alphaproteobacteria) reached $18 \%$ at T275. Litorimonas (Hyphomonadaceae) and Cycloclasticus (Cycloclasticaceae) reached 10 and $6 \%$ of the reads, respectively. 


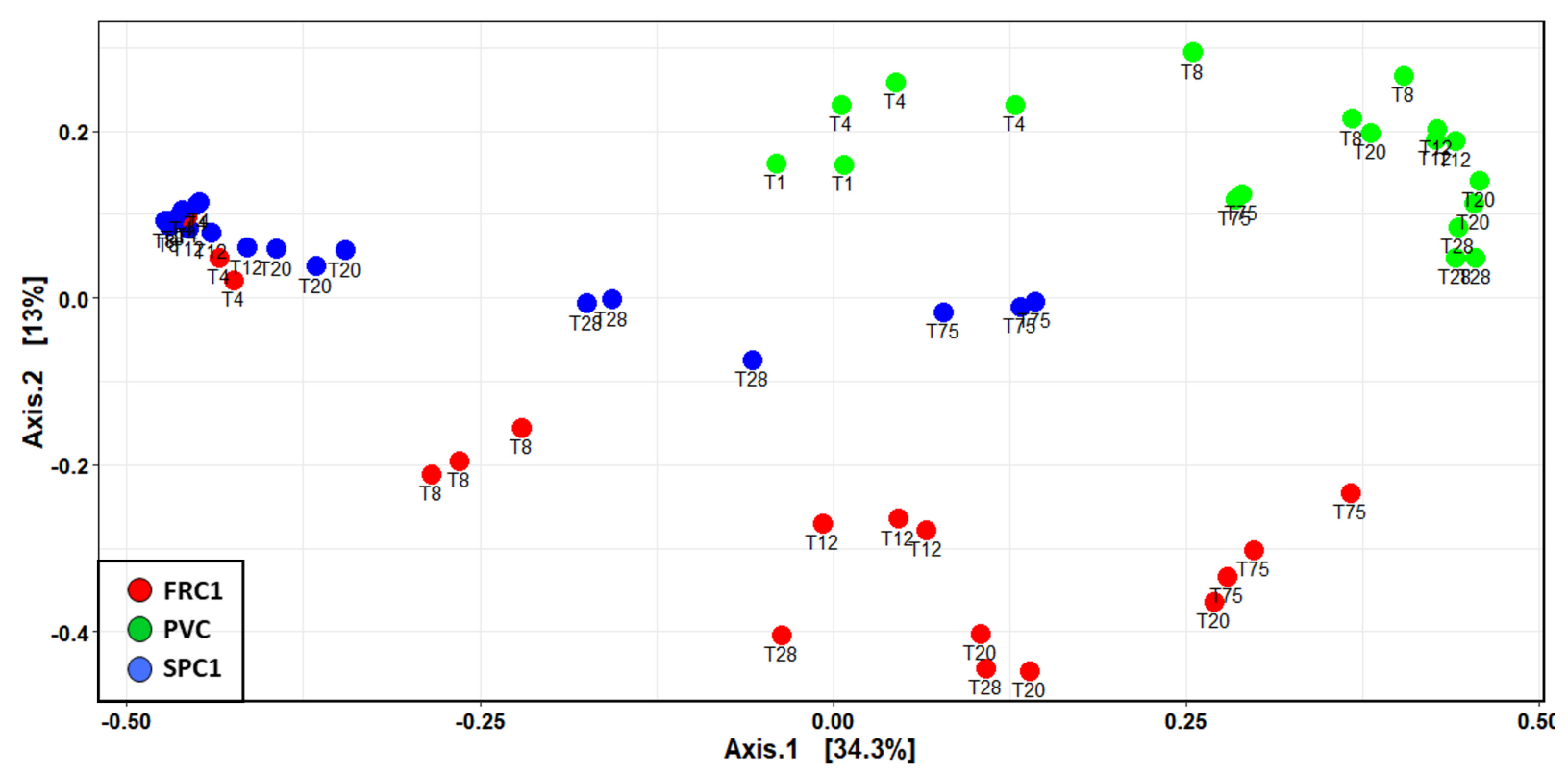

FIGURE 3 | NMDS showing dynamics of prokaryotic communities at Toulon from 1 to 75 days on the three substrates in triplicates (PVC and the two AF coatings, $\mathrm{SPC}$ and FRC) based on Bray and Curtis dissimilarity (Kruskal stress $=0.184$ ).

\section{Spatial Variations of Biofilm Communities}

NMDS based on Bray-Curtis dissimilarities at T75 at the two sites (Figure 5) showed that the main discriminant factor was the presence of copper in coatings, while a significant site effect could be observed only secondarily (PERMANOVA, $p<0.0001$ ).

The dissimilarity between sites on PVC could be assigned mainly to nutrients, metals and salinity, all higher at Toulon (Supplementary Figure 3). Difference in composition on PVC at the two sites was mainly associated with variations in the relative abundance of Cyanobacteria with a highest abundance at Banyuls ( $47 \%$ of reads compared to $16 \%$ at Toulon). In addition filamentous Acrophormium (Phormidesmiaceae) and Oscillatoriaceae dominated at Banyuls while Xenococcus and another Phormidesmiaceae represented the dominant Cyanobacteria at Toulon. Marinicella (Gammaproteobacteria), Blastopirellula (Planctomycetes), several genera among Flavobacteriaceae, Ruegeria and an unknown Rhodobacteriaceae and Saprospiraceae also distinguished biofilms at Banyuls compared to Toulon (Figure 6). SPC1 community at Banyuls differed from PVC at the same site or from the SPC1 at Toulon especially due to a significantly higher proportion of Alteromonas, Aestuariibacter and an unknown Hyphomonadaceae.

Linear discriminant analysis with effect size (LEfSe) was performed at T75 (Figure 7) showing that PVC biomarker at Toulon couldn't be identified. Cyanobacteria (especially Phormidesmiaceae) and Rugiera (Rhodobacteraceae) were specific to PVC at Banyuls, although detected on PVC and FRC1 at both sites. Similarly, Saprospiraceae and unknown Rhobacteraceae appeared as FRC1 biomarkers at Banyuls but were also observed at lower\% on PVC. Caulobacterales (including Litorimonas) as well as Arenicellaceae displayed differential relative abundances on FRC1 at Toulon. Enteromonadales, especially Alteromonas and Aestuariibacter, together with Pseudomonadales, showed differential relative abundances on SPC1 at Banyuls whereas Cytophagales (mainly Fabibacter), Erythrobacter and Marinicella were more specific to SPC1 at Toulon

A co-occurrence network analysis was achieved to identify central ASVs among the mature biofilm communities (T75). 34 nodes (ASVs) constituted the major cluster of the network associated to 159 degrees or edges, corresponding to significant relationships between them (Figure 8 and Supplementary Table 4). Ten genera were represented with specific characteristics. Alteromonas (6 ASVs) and Aestuariibacter (8 ASVs), which were both abundant on SPC1 at both sites, displayed positive edges among themselves while negative ones with Ruegeria and Cyanobacteria (Leptolyngbya and Xenococcus), conversely abundant on PVC and FRC1 at both sites. Gilvibacter (4 ASVs) displayed positive edges among themselves and with Aestuariibacter (1 ASV), while negative edges were observed with one Methyloligellaceae and Leptolyngbia, mostly abundant on FRC1. Hyphomonodaceae mostly exhibited positive edges with Aestuaribacter and negative edges with Ruegeria and Xenococcus. Finally, two Cycloclasticus ASVs, mostly abundant on FRC1 at Toulon, were separated from the main cluster.

\section{DISCUSSION}

\section{Alteromonas, a Pioneer and Copper Resistant Prokaryote Genus}

Alteromonas represented, after 4 days, the early dominant genus with 13,70 , and $89 \%$ of the reads on PVC, FRC1 and SPC1, respectively. However, PVC plates exhibited much more 

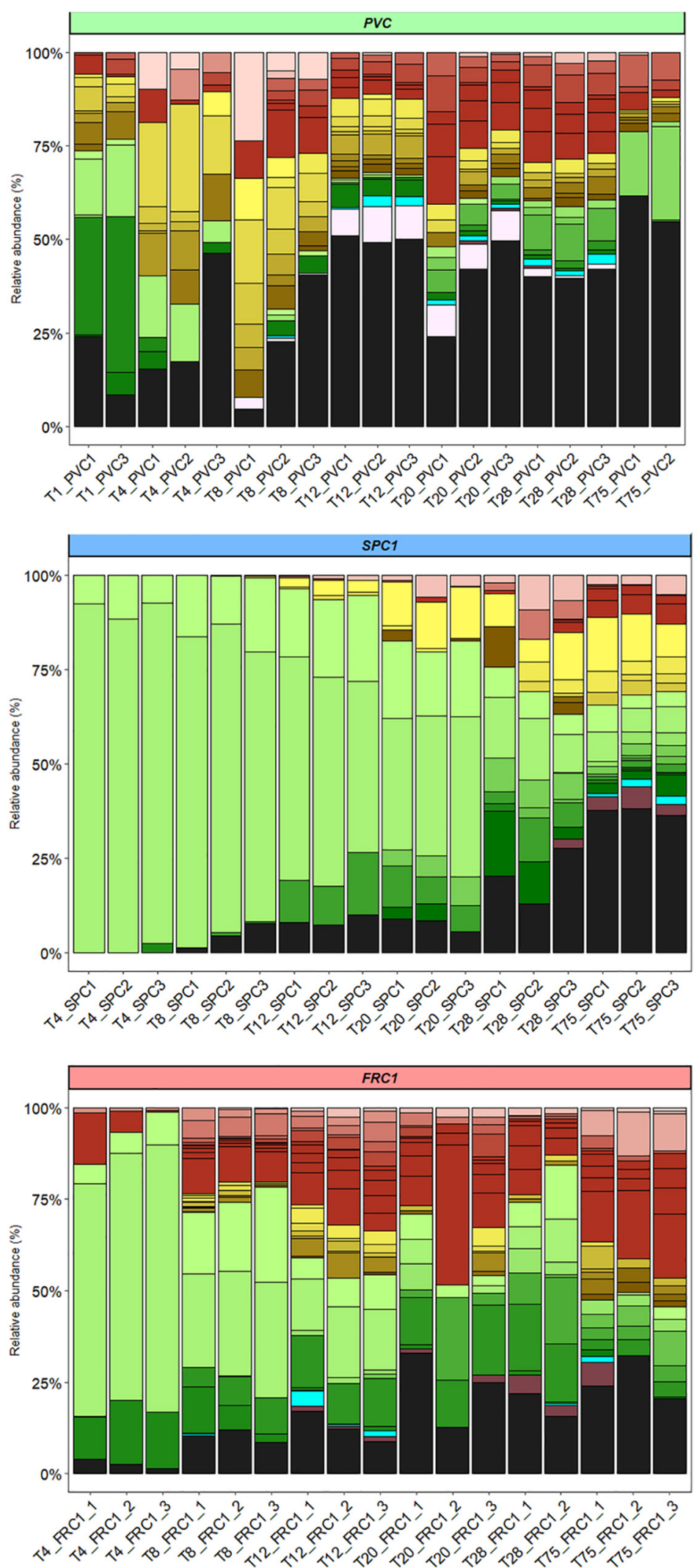

Alphaproteobacteria_Cognatishimia Alphaproteobacteria_Erythrobacter Alphaproteobacteria_Litorimonas Alphaproteobacteria_Nautella Aphaproteobacteria_Pseudophaeobacter Alphaproteobacteria_Ruegeria

Alphaproleobactoria_Tateyamaria

(B)

Bacteroidia_Aurantivirga

(achia

(

Bacteroidia Kordia

Bacteroidia_Lewinell

Bacteroidia_Polaribacter

Bacteroidia Psychroserpens

acteridia

Bacteroidia_unknown genus

Bacteroidia Winogradskyella

Gammaproteobacteria_Aestuariibacter

Gammaproteobacteria_Alteromonas

Gammaproteobacteria Arenicalla

Gammaproteobacteria Candidatus Endoecteinascidia

Gammaproteobacteria_Congregibacter

Gammaproteobacteria_Cycloclasticus

Gammaproteobacteria-Granulosicoccus

Gammaproteobacteria Halioxenophilus

Gammaproteobacteria_Marinobacter

Gammaproteobacteria_Methylotener

Gammaproteobacteria_Oleibacter

Gammaproteobacteria_Thaumasiovibrio

Gammaproteobacteria_unknown genus

OM190_unknown genus

Phycisphaerae_SM1AO2

Verrucomicrobiae_Rubritalea

Others

FIGURE 4 | Dynamics of the relative abundance of the bacterial genera from T1 to T75 for PVC, SPC1, and FRC1 (including replicates) at Toulon. Others corresponded to genera with a relative abundance lower than $0.5 \%$. 


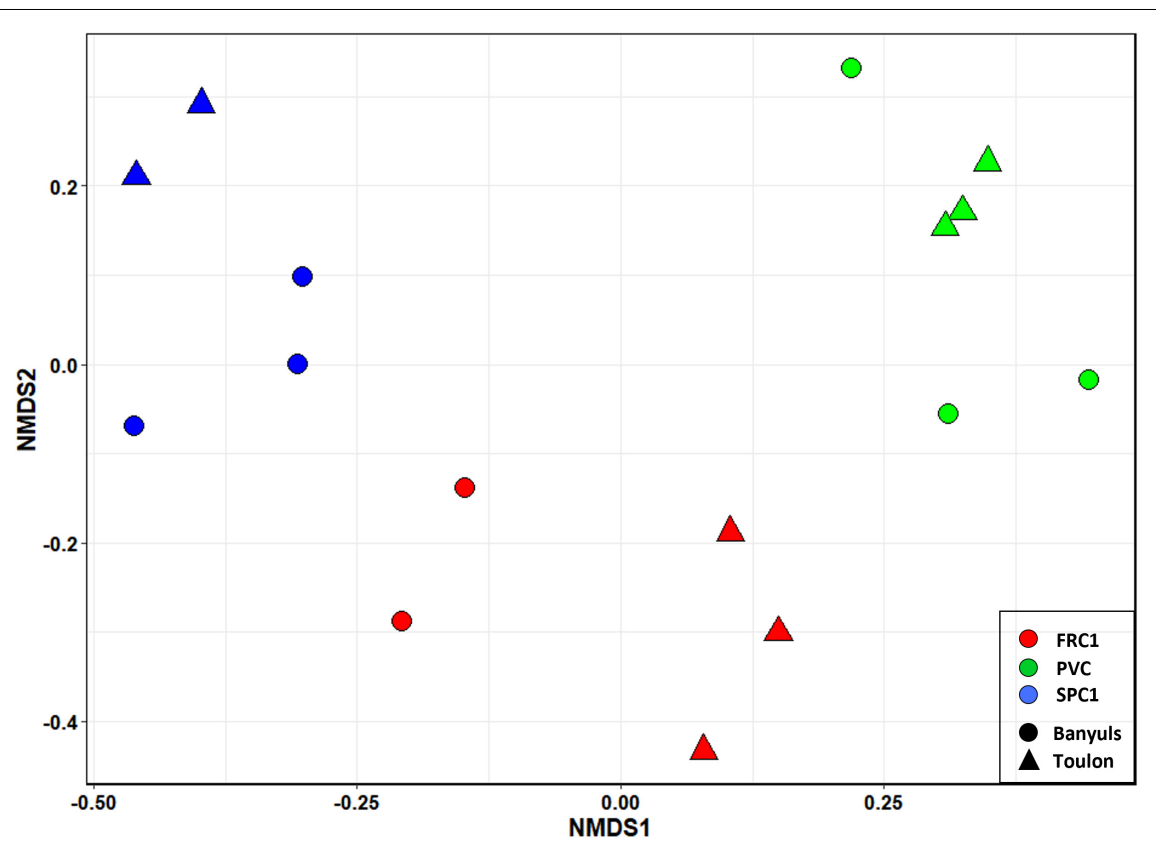

FIGURE 5 | NMDS of the prokaryotic communities on the three substrates in triplicates (PVC, FRC1, and SPC) after 75 days of immersion at Toulon and Banyuls.

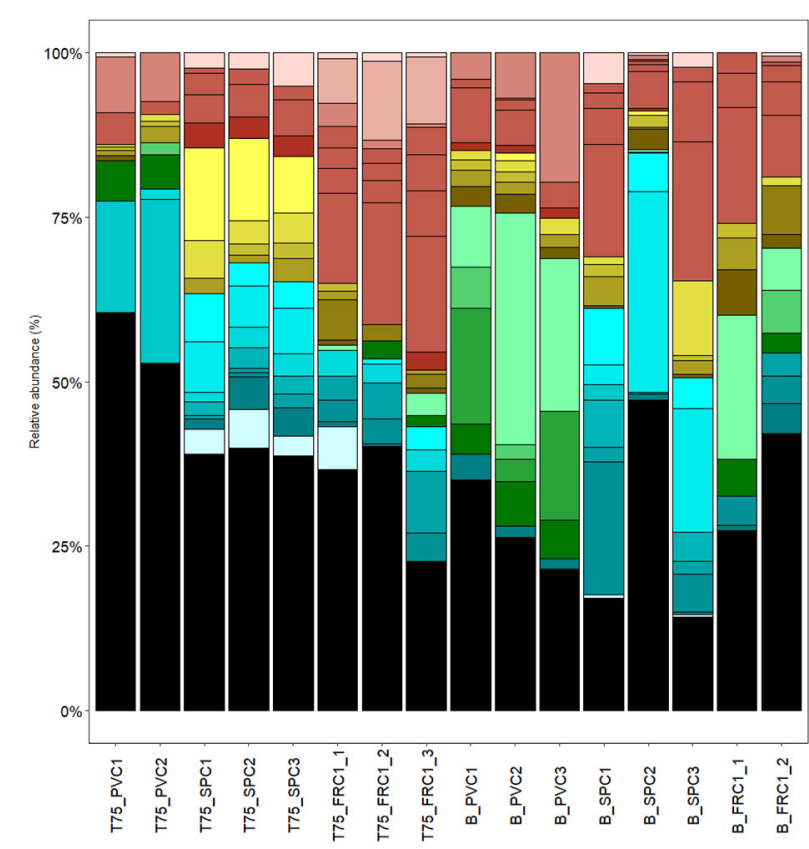

Alphaproteobacteria_Erythrobacter Alphaproteobacteria_Litorimonas Alphaproteobacteria_Ruegeria Alphaproteobacteria_unknown genus A/phaproteobacteria_Yoonia-Loktanella Bacteroidia_Aurantivirga Bacterilia Crocellalea Bacteroida_Dokdonia Bacteroidia_Gilvibacter Bacteroidia_unknown genus

Cyanobacteriia Phormormium PCC-7375
Cyanobacteriia_unknown genus Cyanobacteriia_Xenococcus PCC-7305 Gammaproteobacteria_Aestuariibacter Gammaproteobacteria_Alteromonas Gammaproteobacteria_Arenicella Gammaproteobacteria_Candidatus Endoecteinascidia Gammaproteobacteria_Congregibacter Gammaproteobacteria_Cycloclasticus Gammaprotobacteria_Halloxenophilus Phisponaricell Ohycisphara SM1A0̄

FIGURE 6 | Relative abundance at the genus level after 75 days of immersion at Toulon and Banyuls on the different surfaces (triplicates except PVC at Toulon and FRC1 at Banyuls that displayed only duplicates). Others were genera representing less than $0.5 \%$ of the reads.

diversified communities than SPC ones immersed $10 \mathrm{~cm}$ over. As there is no reason that all early colonizers were resistant to copper, Alteromonas were probably the only pioneers to be resistant to copper. This genus was already mentioned as a pioneer taxa in both temperate and tropical coastal seawaters on plastics on the South Carolina coast (Dang and Lovell, 2000) and the Northern Adriatic (Pinto et al., 2019), and other substrates (acryl, glass, steel, fiberglass) on the Korean coast (Lee et al., 2008) and Indian ocean (Rampadarath et al., 2017). Alteromonas spp. are mainly known as marine generalist copiotrophs, with the ability to degrade a broad range of organic substrates (Dang and Lovell, 2016), especially artificial surface conditioning films. Common adhesion properties like active swimming or surface adhesion mechanisms, involving outer-cell 


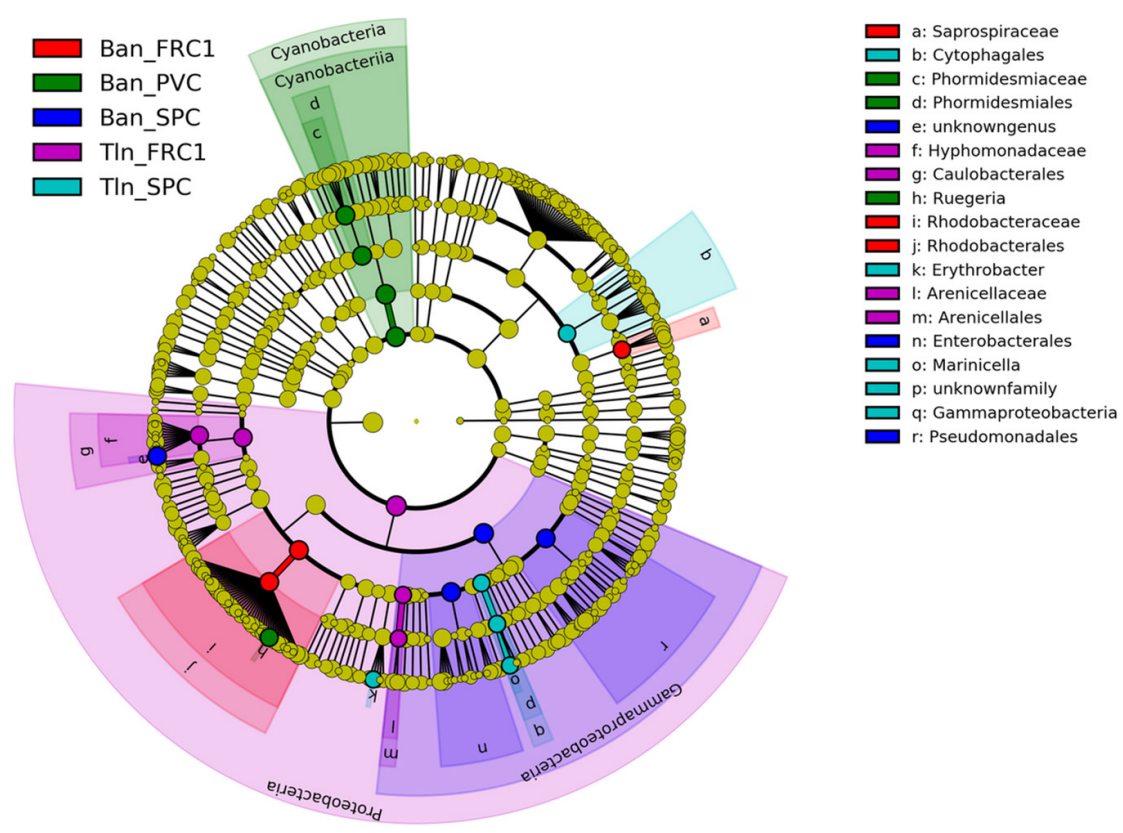

FIGURE 7 | LefSe analysis after 75 days of immersion at Toulon and Banyuls for the three surfaces (PVC, SPC1, and FRC1).

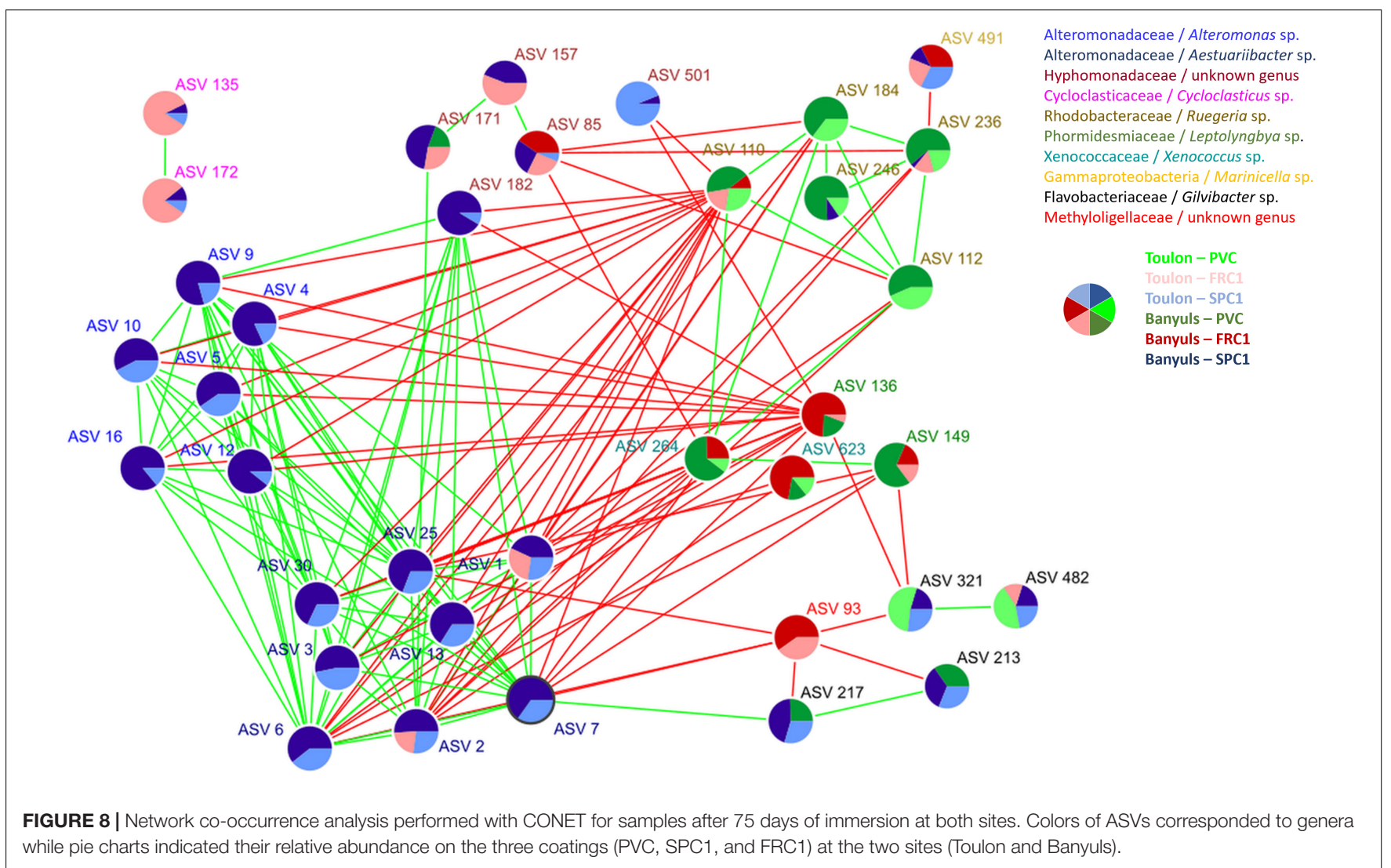

structures (as flagella, fimbriae, pili or curli) or adhesins are not particularly described for Alteromonas. However, the number of genes encoding diguanylate cyclases, which synthetize the c-di-GMP, an intracellular signaling compound that, among other functions, coordinates the transition from a motile to a biofilm lifestyle (Römling et al., 2013), was found higher in A. macleodii than Pseudomonas aeruginosa or Escherichia coli genomes, two biofilm forming model strains (Cusick et al., 2017). 
A gene involved in the lipopolysaccharide synthesis, one of the main components of the outer membrane used to attach to substrates, was also reported by same authors to be highly induced. Moreover, additional cell characteristics may favor early colonization processes too. Its ability to be highly resistant to solar radiation, while non-pigmented (Agogué et al., 2005; Bacosa et al., 2015), may be an additional selective factor, not needed for later colonizers which take advantage of the EPS matrix produced and diatoms presence, in the biofilm community. As a matter of fact, the diversification of the biofilm community on SPC1 involved pigmented diatoms from T4 (data not shown). Moreover, Alteromonas was reported to be a dominant colonizer of copper-based SPCs after 1-4 weeks in marinas from two dissimilar environments, i.e., Singapore (Chen et al., 2013) and the Swedish West coast (Flach et al., 2017). Two hypotheses are generally proposed to explain such a metal resistance/tolerance mechanism: the occurrence of metal resistance genes (MRG) (Flach et al., 2017; Roberto et al., 2019; Catao et al., 2021) and the exopolymeric substances production (EPS) (Flemming et al., 2016). The former was recently demonstrated for several MRG, including copper specific (cusA, copA, and CueO) or not (czcA and pbrT), on substrates including copper-released coatings in the Bay of Toulon but also in a port of the French Atlantic coast in Brittany (Lorient) and in the tropical Indian ocean (Reunion island). Alteromonas showed the strongest correlation at the genus level with cusA whatever the site and coatings (Catao et al., 2021). However, the bay of Toulon appeared unique with high MRG abundance in all biofilm including on PVC after 30 days, together with particular communities on copper based coatings as also shown here. This could indicate that the selection on SPC coatings during the diversification that occurred with time will be based on alternative properties to manage copper like EPS production. Whole-genome sequencing of $A$. macleodii strains, isolated from copper alloy coupons but barely identified in our study, also indicated the presence of Cue, Cus, or Cop systems. They were identified in multiple megaplasmids which are known to be key vectors in horizontal gene transfer (Cusick et al., 2020).

Alteromonas was also identified at Banyuls on SPC1, but with higher relative abundance than at Toulon after 75 days. We may suppose that lower available inorganic nutrients at Banyuls could have slowed down the dynamics compared to Toulon and/or the higher hydrodynamic, experienced at Banyuls due to the location one $\mathrm{km}$ far from the coast with a $27 \mathrm{~m}$ depth, could have maintained unfavorable conditions for biofilm growth as also reflected by lower densities.

\section{Copper-Releasing Coatings Strongly Control Biofilm Density and Diversity Dynamics}

Previous studies have already reported that biocidal coatings exhibited dissimilar communities compared to non-biocidal ones using end-point studies (from a month to a year) in the Oman sea (Muthukrishnan et al., 2014; Dobretsov et al., 2018), the North Western Mediterranean sea (Camps et al., 2014; Briand et al., 2017; Briand et al., 2018; Catão et al., 2019), the Florida coast (Zargiel et al., 2011), the French Atlantic and Indian oceans (Catao et al., 2021) and the Auckland Marina (New Zealand) (von Ammon et al., 2018). However, sequential dynamics have never been studied. Early communities suffered a strong selective pressure due to copper as described above, which explained a lower density and diversity compared to the reference (PVC) for the 75 days of immersion. SPC 1 is a seawater-hydrolyzable coatings with self-polishing behavior (Marceaux et al., 2018). The release of copper ions from this coating relies on both the dissolution of $\mathrm{Cu}_{2} \mathrm{O}$ and the erosion of the polymer matrix. Higher release rate of copper is commonly observed in the early stages of immersion (personal data) before equilibrium is reached between the dissolution kinetics of the biocides and the erosion kinetics of the hydrolyzable polymer matrix. This could result in a potential impact on early bacterial selection. Nevertheless, the biofilm diversity increased with time and Alteromonas spp. became only one of the co-dominant taxa at T75, together with a close phylogenetic-related genus Aestuariibacter, Aurantivirga, Aureisphaera and Croceitalea (Flavobacteriaceae), or Loktanella (Rhodobacteraceae). Some of them even became surface biomarkers like Erythrobacter (Sphingomonadaceae), Most of them were already reported in previous studies including in the Toulon bay like Erythrobacter (Dobretsov et al., 2018; Catão et al., 2019). As physico-chemical parameters didn't vary significantly during the time scale of the experiment (Redundancy analysis not significant, data not shown), additional factor would be involved. Then, as metal resistance genes were not exclusively described for these selected taxa, two hypotheses remained: (i) taxa without adhesion capacities but with copper resistant genes will progressively embed the biofilm community, taking advantages of the matrix generated by early taxa. As copper resistant genes could be shared by horizontal gene transfer among the prokaryotic community, taxa from diversified taxonomic origin were involved, (ii) taxa able to produce EPS, but without particular gene resistance occurrence, were progressively involved in the building of the biofilm structure, as EPS trapped copper released by the coating. The latter hypothesis could join the former as copper resistance genes from early taxa could be spread to the entire biofilm community by horizontal gene transfer which is known to occurred intensively in marine biofilms (Dang and Lovell, 2016).

Similar communities were observed on SPC1 at T75 and after a year of immersion in the same site the same year (Catão et al., 2019). This allowed to conclude that mature communities were reached between 28 and 75 days of immersion in the Bay of Toulon.

\section{Physical Features May Control the Biofilm Density but Not Diversity}

Biofilm dynamics on PVC have been already described in Pollet et al. (2018). Briefly, a rapid and intense colonization of the PVC occurred during the first days following immersion, including a rapid diversification of the biofilm community reaching a highly diversified and stable community after 48 days. Gammaproteobacteria from the genus Oleibacter strongly dominated microbial communities during the first hours of biofilm formation. These pioneer communities were quickly replaced by Alphaproteobacteria and Flavobacteria. We showed that Flavobacteria might be key actors in the functioning of 
marine biofilms. Bacterial communities exhibited fast temporal dynamics with taxa displaying rapid increases and declines. With $2 / 3$ of positive connections between bacterial OTUs, a network analysis showed that biofilm communities were more inclined to develop inter-specific cooperation than competition. The network analysis performed here, including metal-releasing coatings, was conversely dominated by negative connections as discussed below. Cyanobacteria mainly filamentous at Banyuls, but also unicellular (Xenococaceae) at Toulon, were reported as biomarkers of PVC. This implies that no heterotrophic abundant taxa was specific of this surface, which is supported by a high diversity and evenness characteristic of a stabilized (or mature) community, including typical biofilm taxa such as Deltaproteobacteria, Planctomycetes or Verrucomicrobiales. The former belongs to the sulfate-reducing bacteria which found anoxygenic conditions inside the biofilm. Planctomycetes are poorly studied "maverick" bacteria (Wiegand et al., 2018), highly represented in activated sludge and among algal surface associated community. Functions like metal binding extrapolymeric proteins or stress response could explain the success of this taxa among the biofilm community (Bondoso et al., 2017; Chen et al., 2019).

FRCs have been developed to be alternatives to biocidal coatings and more environmentally friendly AF strategies. FRCs aimed to minimize the adhesion of fouling organisms on ship hulls, so that they can be removed by hydrodynamic stress during navigation or by a simple mechanical cleaning. In addition, the smoothness of FRCs enables them to reduce the drag of the vessel and therefore reduce fuel consumption and greenhouse gas emissions (Lejars et al., 2012). FRC1 properties actually limited the prokaryotic colonization, exhibiting the lowest density throughout the study at Toulon, ten times less than PVC after 75 days of immersion. Community dynamics appeared also definitely slowed compared to the PVC, with early stages showing a lower alpha diversity with the dominance of Alteromonas, as for SPC1. This genus was already reported to be an early colonizer on plastics (Pinto et al., 2019). Its ability to attach to such smooth, soft and amphiphilic FRC1 surface confirmed a great potential of adhesion which would be interesting to better characterize, as several mechanisms including flagella, pili, curli, holdfast or EPS production could be involved (Flemming and Wingender, 2010; Cusick et al., 2017). Cusick et al. (2020) mentioned that metal resistance genes were not detected in all Alteromonas strains, but only in those isolated from copper alloy coupons. However, Catao et al. (2021) recently reported that MRG showed similar occurrence in biofilm from both AF and PVC surfaces especially in the Toulon bay, with probable link to a long history of metal contamination. This is in accordance with the fact that identical early colonizers could be identified on SPC1 and FRC1 here. Oleibacter, as for PVC and an additional Alteromonadaceae genus (Aestuaribacter), completed the early communities on FRC1, which allow to hypothesize that early colonizers on PVC were potentially not fully described with a sampling after $24 \mathrm{~h}$, all the more that the alpha diversity was already high. Both local seawater (see below) and physical surface characteristics control the temporal dynamics, which could explain why early colonizers described in the literature were diverse. Only the study of the dynamics may allow to definitely identified early colonizers at one site. However, the diversification and the concurrent increase of the diversity of the biofilm community on FRC1 occurred during the 12-20 days of immersion, with a convergence of the assemblage on the PVC as clearly showed by the NMDS (Figure 3). Similar clustering was kept at very long immersion time (1 year), including in dynamic conditions (Catão et al., 2019). The similarity of mature communities on PVC and FRC1 appeared consistent with the already reported low influence of the plastic type on mature biofilm community structures when immersed at the same location (Lee et al., 2014; Kirstein et al., 2018; Pinto et al., 2019). Physical properties of substrates like wettability, roughness or softness have been described to limit the microbial density and select only early communities as also observed in South Carolina (Dang and Lovell, 2000), South Korea (Lee et al., 2008) or Croatia (Pinto et al., 2019). We clearly conclude that physical factors of substrate lose their influence on bacterial community structure with time.

\section{Spatial Biofilm Community Dissimilarities Between the Two Mediterranean Sites Could Be Associated to Variations in Hydrodynamics and Seawater Metals Concentrations}

Previous comparisons with sites in the Atlantic or Indian oceans already showed us that temperature, salinity, nutrients and metals could shape dissimilar biofilm communities on both plastic and AF surfaces (Briand et al., 2017; Catao et al., 2021). Salinity was also proposed to be a key biofilm community driver on plastics in the Baltic sea (Oberbeckmann et al., 2018). However, these sites exhibited several different environmental characteristics which implies a complex multifactorial control and we intended to test closer environmental conditions that could be found in the same Mediterranean region, where temperature and salinity are similar and mostly the anthropic impact changes with lower nutrients and metal contaminants availability in the Bay of Banyuls.

If SPC1 and FRC1 at both locations exhibited lower densities compared to PVC, they both seemed more efficient antifoulings at Banyuls, probably taking advantage of a higher hydrodynamics. Indeed, the location of the SOLA buoy, $1 \mathrm{~km}$ far from the coast with a $27 \mathrm{~m}$ depth, implies stronger currents that could limit biofilm densities, probably together with the lower nutrients availability, as also already reported on 1 year old biofilms (Catão et al., 2019). Moreover, it may have also accelerated the coating erosion and release of copper, increasing the SPCs efficacy (Bressy et al., 2009). As observed at Toulon, biofilms at Banyuls on SPC1 were clearly dissimilar from the ones on PVC and FRC1, the latter in addition showing a higher similarity. $\alpha$ diversity was similar on both locations for the different coatings but, as mentioned above, hydrodynamics and perhaps low nutrient availability, may have slowed biofilm dynamics on SPC1, explaining a higher Alteromonas relative abundance at Banyuls. In addition, the significant discrepancy between sites on SPC1 was also associated to the occurrence of an unknown genus of Hyphomonadaceae, which are known to produce a polar holdfast enabling the attachment on surfaces. 
Such functional feature provides a selective advantage as pioneer taxa (Langille and Weiner, 1998; Dang and Lovell, 2016), which reinforces the hypothesis of a less mature biofilm on SPC1 at Banyuls. Considering FRC1, higher currents at Banyuls surely favorized the detachment of biofilm as such coatings are designed to minimize the attachment forces through low surface energy, roughness and elastic modulus. These high fouling release properties could explain its higher efficiency at Banyuls compared to Toulon.

Moreover, Desulfovibrionaceae (Halodesulfovibrio) and a tunicate endosymbiont (Candidatus endocteinascidia) (PérezMatos et al., 2007) were two of the five taxa explaining most of the dissimilarity between highly diversified biofilms on PVC at Toulon and Banyuls (SIMPER analysis), and representing higher relative percentages of reads at Toulon. Desulfovibrionaceae belongs to Deltaproteobacteria and especially anaerobic sulfatereducing bacteria. They are well known to develop in the central part of mature biofilms which is characterized by low oxygen amounts (McDougald et al., 2011). Tunicates are invertebrate macrofoulers often observed at the bay of Toulon after several weeks of immersion on PVC (Briand et al., 2018) and consistent with visual observations (Supplementary Figure 3).

ASVs highlighted with the co-occurrence network analysis and that belong to PVC communities, were Rugiera (Rhodobacteraceae), Gilvibacter (Flavobacteriaceae) but also Cyanobacteria. Especially, Banyuls biofilms on PVC exhibited a large community of Cyanobacteria. If the coccoid Xenococcus occurred at both sites, filamentous Nostocales and Phormidesmiaceae displayed high relative percentages (around $47 \%$ ) on PVC at Banyuls. Such specificity, compared to other sites in harbors or marinas studied elsewhere, could be linked to the low metal seawater concentrations, especially copper derivatives which are widely used as algicides. Using a $16 \mathrm{~S}$ rRNA sequencing approach, only one other study reported Cyanobacteria as main contributors of biofilm community on artificial substrates in a marina in the Oman sea, but including AF coatings (Muthukrishnan et al., 2014). These may indicate that these diversified Cyanobacteria (coccoids and filamentous taxa including Acaryochloris, Phormidium, Leptolyngbya, or Oscillatoria) were probably adapted to high metal concentrations, conversely to our study.

Apart from density, nutrients availability, in the range we experienced in the mesotrophic Bay of Toulon and oligotrophic Bay of Banyuls, did not appear to be a strong driver of community structure as copiotrophs, especially among Gammaproteobacteria, reputed to be encouraged to grow in nutrient enriched systems (Lawes et al., 2016), which were not particularly more abundant at Toulon. When reported as biofilm community drivers in the Baltic Sea, inorganic nutrients displayed a much more higher range, reaching hyper eutrophic levels (Oberbeckmann et al., 2018; Kesy et al., 2019).

\section{CONCLUSION}

This study shows that both surface characteristics and environmental parameters control colonization. However, even if local environmental seawater characteristics influence biofilms, copper-releasing coatings apply a huge quantitative and qualitative selective pressure on microbial colonizers while particular surface physical characteristics control only density. Hydrodynamics could limit densities but also slow down biofilm dynamics. Finally, sequential biofilm dynamics should be carefully considered as initial processes differed from long-term ones.

\section{DATA AVAILABILITY STATEMENT}

The datasets presented in this study can be found in online repositories. The names of the repository/repositories and accession number(s) can be found below: https://www.ncbi.nlm. nih.gov/, PRJNA648348.

\section{AUTHOR CONTRIBUTIONS}

J-FB performed the immersion experiments, performed the sampling at Banyuls, formal analysis, and interpretation of the Illumina Miseq data with AP, wrote the original draft, supervised the project. TP executed the immersion experiments and sampling at Toulon ad Banyuls, the PCR for Illumina Miseq, formal analysis of the Illumina Miseq, review the draft. BM performed flow cytometry analyses and interpretation and reviewed the draft. CG analyzed and interpreted seawater chemical analyses. ML and MM painted the panels and executed the immersion experiments at Toulon. RB-M executed the immersion experiments and sampling at Toulon. J-FG reviewed and edited the draft. CB performed the immersion experiments, especially the choice of the antifouling coatings, supervised the global project, wrote, and edited the draft. All authors contributed to the article and approved the submitted version.

\section{FUNDING}

This work was supported by the Direction Générale de l'Armement, French Government Defense Procurement and Technology Agency (DRACONS Program).

\section{ACKNOWLEDGMENTS}

We thank Lucile Pelloquet for her help in the follow up of the immerged panels at Toulon and the scuba diving service of the Oceanographic Observatory of Banyuls-sur-Mer (OOB) for the immersion at the SOLA Buoy at Banyuls. We also thank S. Leterme (Flinders University, South Australia) for English editing.

\section{SUPPLEMENTARY MATERIAL}

The Supplementary Material for this article can be found online at: https://www.frontiersin.org/articles/10.3389/fmars.2021. 746383/full\#supplementary-material 


\section{REFERENCES}

Agogué, H., Joux, F., Obernosterer, I., and Lebaron, P. (2005). Resistance of marine bacterioneuston to solar radiation. Appl. Environ. Microbiol. 71, 5282-5289. doi: 10.1128/AEM.71.9.5282-5289.2005

Bacosa, H. P., Liu, Z., and Erdner, D. L. (2015). Natural sunlight shapes crude oildegrading bacterial communities in Northern Gulf of Mexico surface waters. Front. Microbiol. 6:1325. doi: 10.3389/fmicb.2015.01325

Bondoso, J., Godoy-Vitorino, F., Balagué, V., Gasol, J. M., Harder, J., and Lage, O. M. (2017). Epiphytic planctomycetes communities associated with three main groups of macroalgae. FEMS Microbiol. Ecol. 93:fiw255. doi: 10.1093/ femsec/fiw255

Bressy, C., Margaillan, A., Fay, F., Linossier, I., and Réhel, K. (2009). “Tin-free self-polishing marine antifouling coatings," in Advances in Marine Antifouling Coatings and Technologies, eds C. Hellio and D. M. Yebra (Cambridge: Woodshead Publishing), 445-491. doi: 10.1016/S0025-326X(03)00044-4

Briand, J.-F., Barani, A., Garnier, C., Réhel, K., Urvois, F., Lepoupon, C., et al. (2017). Spatio-temporal variations of marine biofilm communities colonizing artificial substrata including antifouling coatings in contrasted French coastal environments. Microb. Ecol. 74, 585-598. doi: 10.1007/s00248-017-0966-2

Briand, J.-F., Djeridi, I., Jamet, D., Coupé, S., Bressy, C., Molmeret, M., et al. (2012). Pioneer marine biofilms on artificial surfaces including antifouling coatings immersed in two contrasting French Mediterranean coast sites. Biofouling 28 453-463. doi: 10.1080/08927014.2012.688957

Briand, J.-F., Pochon, X., Wood, S. A., Bressy, C., Garnier, C., Réhel, K., et al. (2018). Metabarcoding and metabolomics offer complementarity in deciphering marine eukaryotic biofouling community shifts. Biofouling 34, 657-672. doi: 10.1080/08927014.2018.1480757

Callahan, B. J., Mcmurdie, P. J., Rosen, M. J., Han, A. W., Johnson, A. J. A., and Holmes, S. P. (2016). DADA2: high-resolution sample inference from Illumina amplicon data. Nat. Methods 13, 581-583. doi: 10.1038/nmeth.3869

Camps, M., Barani, A., Gregori, G., Bouchez, A., Le Berre, B., Bressy, C., et al. (2014). Antifouling coatings influence both abundance and community structure of colonizing biofilms: a case study in the Northwestern Mediterranean Sea. Appl. Environ. Microbiol. 80, 4821-4831. doi: 10.1128/ AEM.00948-14

Catao, E. C. P., Gallois, N., Fay, F., Misson, B., and Briand, J.-F. (2021). Metal resistance genes enrichment in marine biofilm communities selected by biocide-containing surfaces in temperate and tropical coastal environments. Environ. Pollut. 268:115835. doi: 10.1016/j.envpol.2020.115835

Catão, E. C. P., Pollet, T., Misson, B., Garnier, C., Ghiglione, J.-F., Barry-Martinet, R., et al. (2019). Shear stress as a major driver of marine biofilm communities in the NW Mediterranean Sea. Front. Microbiol. 10:1768. doi: 10.3389/fmicb.2019. 01768

Chen, C.-L., Maki, J. S., Rittschof, D., and Teo, S. L.-M. (2013). Early marine bacterial biofilm on a copper-based antifouling paint. Int. Biodeter. Biodegrad. $83,71-76$.

Chen, Z., Meng, Y., Sheng, B., Zhou, Z., Jin, C., and Meng, F. (2019). Linking exoproteome function and structure to anammox biofilm development. Environ. Sci. Technol. 53, 1490-1500. doi: 10.1021/acs.est.8b04397

Cindric, A. M., Garnier, C., Oursel, B., Pizeta, I., and Omanovic, D. (2015). Evidencing the natural and anthropogenic processes controlling trace metals dynamic in a highly stratified estuary: the Krka River estuary (Adriatic, Croatia). Mar. Pollut. Bull. 94, 199-216. doi: 10.1016/j.marpolbul.2015.02.029

Coclet, C., Garnier, C., Delpy, F., Jamet, D., Durrieu, G., Le Poupon, C., et al. (2018). Trace metal contamination as a toxic and structuring factor impacting ultraphytoplankton communities in a multicontaminated Mediterranean coastal area. Progr. Oceanogr. 163, 196-213. doi: 10.1016/j.pocean.2017.06.006

Curren, E., and Leong, S. C. Y. (2018). Profiles of bacterial assemblages from microplastics of tropical coastal environments. Sci. Total Environ. 655, 313-320. doi: 10.1016/j.scitotenv.2018.11.250

Cusick, K. D., Dale, J. R., Fitzgerald, L. A., Little, B. J., and Biffinger, J. C. (2017). Adaptation to copper stress influences biofilm formation in Alteromonas macleodii. Biofouling 33, 505-519. doi: 10.1080/08927014.2017.1329423

Cusick, K. D., Polson, S. W., Duran, G., and Hill, R. T. (2020). Multiple megaplasmids confer extremely high levels of metal tolerance in Alteromonas strains. Appl. Environ. Microbiol. 86:17. doi: 10.1128/AEM.01831-19
Dang, H., and Lovell, C. R. (2000). Bacterial primary colonization and early succession on surfaces in marine waters as determined by amplified rRNA gene restriction analysis and sequence analysis of $16 \mathrm{~S}$ rRNA genes. Appl. Environ. Microbiol. 66, 467-475. doi: 10.1128/AEM.66.2.467-475.2000

Dang, H., and Lovell, C. R. (2016). Microbial surface colonization and biofilm development in marine environments. Microbiol. Mol. Biol. Rev. 80, 91-138. doi: 10.1128/MMBR.00037-15

de Carvalho, C. C. C. R. (2018). Marine biofilms: a successful microbial strategy with economic implications. Front. Mar. Sci. 5:126. doi: 10.3389/fmars.2018. 00126

Delgado, A., Briciu-Burghina, C., and Regan, F. (2021). Antifouling strategies for sensors used in water monitoring: review and future perspectives. Sensors 21:389. doi: 10.3390/s21020389

Ding, W., Zhang, W., Alikunhi, N. M., Batang, Z., Pei, B., Wang, R., et al. (2019). Metagenomic analysis of zinc surface-associated marine biofilms. Microb. Ecol. 77, 406-416. doi: 10.1007/s00248-018-01313-3

Dobretsov, S., Abed, R. M. M., Muthukrishnan, T., Sathe, P., Al-Naamani, L., Queste, B. Y., et al. (2018). Living on the edge: biofilms developing in oscillating environmental conditions. Biofouling 34, 1064-1077. doi: 10.1080/08927014. 2018.1539707

Duong, T. H., Briand, J.-F., Margaillan, A., and Bressy, C. (2015). Polysiloxanebased block copolymers with marine bacterial anti-adhesion properties. Appl. Mater. Interfaces 7, 15578-15586. doi: 10.1021/acsami.5b04234

Faust, K., and Raes, J. (2016). CoNet app: inference of biological association networks using Cytoscape. F1000Research 5:1519. doi: 10.12688/f1000research. 9050.2

Flach, C.-F., Pal, C., Svensson, C. J., Kristiansson, E., Östman, M., BengtssonPalme, J., et al. (2017). Does antifouling paint select for antibiotic resistance? Sci. Total Environ. 590-591, 461-468. doi: 10.1016/j.scitotenv.2017.01.213

Flemming, H. C., Wingender, J., Szewzyk, U., Steinberg, P., Rice, S. A., and Kjelleberg, S. (2016). Biofilms: an emergent form of bacterial life. Nat. Rev. Microbiol. 14, 563-575. doi: 10.1038/nrmicro.2016.94

Flemming, H.-C., and Wingender, J. (2010). The biofilm matrix. Nat. Rev. Microbiol. 8, 623-633. doi: 10.3390/nano10081527

Frere, L., Maignien, L., Chalopin, M., Huvet, A., Rinnert, E., Morrison, H., et al. (2018). Microplastic bacterial communities in the bay of brest: influence of polymer type and size. Environ. Pollut. 242, 614-625. doi: 10.1016/j.envpol. 2018.07.023

Genzer, J., and Efimenko, K. (2006). Recent developments in superhydrophobic surfaces and their relevance to marine fouling: a review. Biofouling 22, 339-360. doi: 10.1080/08927010600980223

Hadfield, M. G. (2011). Biofilms and marine invertebrate larvae: what bacteria produce that larvae use to choose settlement sites. Ann. Rev. Mar. Sci. 3, 453-470. doi: 10.1146/annurev-marine-120709-142753

Jacquin, J., Cheng, J., Odobel, C., Pandin, C., Conan, P., Pujo-Pay, M., et al. (2019). Microbial ecotoxicology of marine plastic debris: a review on colonization and biodegradation by the "plastisphere". Front. Microbiol. 10:865. doi: 10.3389/ fmicb.2019.00865

Kesy, K., Oberbeckmann, S., Kreikemeyer, B., and Labrenz, M. (2019). Spatial environmental heterogeneity determines young biofilm assemblages on microplastics in Baltic Sea mesocosms. Front. Microbiol. 10:1665. doi: 10.3389/ fmicb.2019.01665

Kirstein, I. V., Wichels, A., Krohne, G., and Gerdts, G. (2018). Mature biofilm communities on synthetic polymers in seawater - Specific or general? Mar. Environ. Res. 142, 147-154. doi: 10.1016/j.marenvres.2018.09.028

Langille, S. E., and Weiner, R. M. (1998). Spatial and temporal deposition of Hyphomonas strain VP-6 capsules involved in biofilm formation. Appl. Environ. Microbiol. 64, 2906-2913. doi: 10.1128/AEM.64.8.2906-2913.1998

Lawes, J. C., Neilan, B. A., Brown, M. V., Clark, G. F., and Johnston, E. L. (2016) Elevated nutrients change bacterial community composition and connectivity: high throughput sequencing of young marine biofilms. Biofouling 32, 57-69. doi: 10.1080/08927014.2015.1126581

Lee, J.-W., Nam, J.-H., Kim, Y.-H., Lee, K.-H., and Lee, D.-H. (2008). Bacterial communities in the initial stage of marine biofilm formation on artificial surfaces. J. Microbiol. 46, 174-182. doi: 10.1007/s12275-008-0032-3

Lee, O. O., Wang, Y., Tian, R. M., Zhang, W. P., Shek, C. S., Bougouffa, S., et al. (2014). In situ environment rather than substrate type dictates microbial 
community structure of biofilms in a cold seep system. Sci. Rep. 4:3587. doi: 10.1038/srep03587

Lejars, M., Margaillan, A., and Bressy, C. (2012). Fouling release coatings: a nontoxic alternative to biocidal antifouling coatings. Chemical Reviews 112, 4347-4390. doi: 10.1021/cr200350v

Lema, K. A., Constancias, F., Rice, S. A., and Hadfield, M. G. (2019). High bacterial diversity in nearshore and oceanic biofilms and their influence on larval settlement by Hydroides elegans (Polychaeta). Environ. Microbiol. 21, 3472-3488. doi: 10.1111/1462-2920.14697

Marceaux, S., Martin, C., Margaillan, A., and Bressy, C. (2018). Effects of accelerated ageing conditions on the mechanism of chemically-active antifouling coatings. Progr. Organic Coat. 125, 257-265.

McDougald, D., Rice, S. A., Barraud, N., Steinberg, P. D., and Kjelleberg, S. (2011). Should we stay or should we go: mechanisms and ecological consequences for biofilm dispersal. Nat. Rev. Microbiol. 10, 39-50. doi: 10.1038/nrmicro2695

Muthukrishnan, T., Abed, R. M. M., Dobretsov, S., Kidd, B., and Finnie, A. A. (2014). Long-term microfouling on commercial biocidal fouling control coatings. Biofouling 30, 1155-1164. doi: 10.1080/08927014.2014.972951

Muthukrishnan, T., Al Khaburi, M., and Abed, R. M. M. (2019). Fouling microbial communities on plastics compared with wood and steel: are they substrate- or location-specific? Microb. Ecol. 78, 361-374. doi: 10.1007/s00248-018-1303-0

Oberbeckmann, S., and Labrenz, M. (2020). Marine microbial assemblages on microplastics: diversity, adaptation, and role in degradation. Ann. Rev. Mar. Sci. 12, 209-232. doi: 10.1146/annurev-marine-010419-010633

Oberbeckmann, S., Kreikemeyer, B., and Labrenz, M. (2018). Environmental factors support the formation of specific bacterial assemblages on microplastics. Front. Microbiol. 8:2709. doi: 10.3389/fmicb.2017.02709

Oberbeckmann, S., Osborn, A. M., and Duhaime, M. B. (2016). Microbes on a bottle: substrate, season and geography influence community composition of microbes colonizing marine plastic debris. PLoS One 11:e0159289. doi: 10.1371/ journal.pone.0159289

Ogonowski, M., Motiei, A., Ininbergs, K., Hell, E., Gerdes, Z., Udekwu, K. I., et al. (2018). Evidence for selective bacterial community structuring on microplastics. Environ. Microbiol. 20, 2796-2808. doi: 10.1111/1462-2920. 14120

Oursel, B., Garnier, C., Durrieu, G., Mounier, S., Omanovic, D., and Lucas, Y. (2013). Dynamics and fates of trace metals chronically input in a Mediterranean coastal zone impacted by a large urban area. Marine Pollution Bulletin 69, 137-149. doi: 10.1016/j.marpolbul.2013.01.023

Parada, A. E., Needham, D. M., and Fuhrman, J. A. (2016). Every base matters: assessing small subunit rRNA primers for marine microbiomes with mock communities, time series and global field samples. Environ. Microbiol. 18, 1403-1414. doi: 10.1111/1462-2920.13023

Pérez-Matos, A. E., Rosado, W., and Govind, N. S. (2007). Bacterial diversity associated with the Caribbean tunicate Ecteinascidia turbinata. Antonie Van Leeuwenhoek 92, 155-164. doi: 10.1007/s10482-007-9143-9

Pinto, M., Langer, T. M., Huffer, T., Hofmann, T., and Herndl, G. J. (2019). The composition of bacterial communities associated with plastic biofilms differs between different polymers and stages of biofilm succession. PLoS One 14:e0217165. doi: 10.1371/journal.pone.0217165

Piola, R. F., Dafforn, K. A., and Johnston, E. L. (2009). The influence of antifouling practices on marine invasions. Biofouling 25, 633-644. doi: 10.1080/ 08927010903063065

Pollet, T., Berdjeb, L., Garnier, C., Durrieu, G., Le Poupon, C., Misson, B., et al. (2018). Prokaryotic community successions and interactions in marine biofilms: the key role of Flavobacteriia. FEMS Microbiol. Ecol. 94:fiy083. doi: 10.1093/femsec/fiy083

Rampadarath, S., Bandhoa, K., Puchooa, D., Jeewon, R., and Bal, S. (2017). Early bacterial biofilm colonizers in the coastal waters of Mauritius. Electron. J. Biotechnol. 29, 13-21. doi: 10.1016/j.ejbt.2017.06.006

Roberto, A. A., Van Gray, J. B., Engohang-Ndong, J., and Leff, L. G. (2019). Distribution and co-occurrence of antibiotic and metal resistance genes in biofilms of an anthropogenically impacted stream. Sci. Total Environ. 688, 437-449. doi: 10.1016/j.scitotenv.2019.06.053
Römling, U., Galperin, M. Y., and Gomelsky, M. (2013). Cyclic di-GMP: the first 25 years of a universal bacterial second messenger. Microbiol. Mol. Biol. Rev. 77, 1-52. doi: 10.1128/MMBR.00043-12

Salta, M., Wharton, J. A., Blache, Y., Stokes, K. R., and Briand, J.-F. (2013). Marine biofilms on artificial surfaces: structure and dynamics. Environ. Microbiol. 15, 2879-2893. doi: 10.1111/1462-2920.12186

Sardain, A., Sardain, E., and Leung, B. (2019). Global forecasts of shipping traffic and biological invasions to 2050. Nat. Sustain. 2, 274-282. doi: 10.1038/s41893019-0245-y

Sathe, P., Laxman, K., Myint, M. T. Z., Dobretsov, S., Richter, J., and Dutta, J. (2017). Bioinspired nanocoatings for biofouling prevention by photocatalytic redox reactions. Sci. Rep. 7:12. doi: 10.1038/s41598-017-03636-6

Sathe, P., Richter, J., Myint, M. T. Z., Dobretsov, S., and Dutta, J. (2016). Selfdecontaminating photocatalytic zinc oxide nanorod coatings for prevention of marine microfouling: a mesocosm study. Biofouling 32, 383-395. doi: 10.1080/ 08927014.2016 .1146256

Segata, N., Izard, J., Waldron, L., Gevers, D., Miropolsky, L., Garrett, W. S., et al. (2011). Metagenomic biomarker discovery and explanation. Genome Biol. 12:R60. doi: 10.1186/gb-2011-12-6-r60

Shannon, P., Markiel, A., Ozier, O., Baliga, N. S., Wang, J. T., Ramage, D., et al. (2003). Cytoscape: a software environment for integrated models of biomolecular interaction networks. Genome Res. 13, 2498-2504. doi: 10.1101/ gr.1239303

von Ammon, U., Wood, S. A., Laroche, O., Zaiko, A., Tait, L., Lavery, S., et al. (2018). The impact of artificial surfaces on marine bacterial and eukaryotic biofouling assemblages: a high-throughput sequencing analysis. Mar. Environ. Res. 133, 57-66. doi: 10.1016/j.marenvres.2017.12.003

Webster, N. S., and Negri, A. P. (2006). Site-specific variation in antarctic marine biofilms established on artificial surfaces. Environ. Microbiol. 8, 1177-1190. doi: 10.1111/j.1462-2920.2006.01007.x

Wiegand, S., Jogler, M., and Jogler, C. (2018). On the maverick Planctomycetes. FEMS Microbiol. Rev. 42, 739-760. doi: 10.1093/femsre/fuy029

Yang, J. L., Li, Y.-F., Liang, X., Guo, X.-P., Ding, D.-W., Zhang, D., et al. (2016a). Silver nanoparticles impact biofilm communities and mussel settlement. Sci. Rep. 6:37406. doi: 10.1038/srep37406

Yang, J. L., Li, Y. F., Guo, X. P., Liang, X., Xu, Y. F., Ding, D. W., et al. (2016b) The effect of carbon nanotubes and titanium dioxide incorporated in PDMS on biofilm community composition and subsequent mussel plantigrade settlement. Biofouling 32, 763-777. doi: 10.1080/08927014.2016.1197210

Zargiel, K. A., Coogan, J. S., and Swain, G. W. (2011). Diatom community structure on commercially available ship hull coatings. Biofouling 27, 955-965. doi: 10 . 1080/08927014.2011.618268

Zhang, W., Ding, W., Li, Y.-X., Tam, C., Bougouffa, S., Wang, R., et al. (2019). Marine biofilms constitute a bank of hidden microbial diversity and functional potential. Nat. Commun. 10:517. doi: 10.1038/s41467-019-08463-Z

Conflict of Interest: The authors declare that the research was conducted in the absence of any commercial or financial relationships that could be construed as a potential conflict of interest.

Publisher's Note: All claims expressed in this article are solely those of the authors and do not necessarily represent those of their affiliated organizations, or those of the publisher, the editors and the reviewers. Any product that may be evaluated in this article, or claim that may be made by its manufacturer, is not guaranteed or endorsed by the publisher.

Copyright (C) 2022 Briand, Pollet, Misson, Garnier, Lejars, Maintenay, BarryMartinet, Portas, Ghiglione and Bressy. This is an open-access article distributed under the terms of the Creative Commons Attribution License (CC BY). The use, distribution or reproduction in other forums is permitted, provided the original author(s) and the copyright owner(s) are credited and that the original publication in this journal is cited, in accordance with accepted academic practice. No use, distribution or reproduction is permitted which does not comply with these terms. 